\title{
Americanismo y latinoamericanismo
}

\section{Dos momentos en la constitución de un espacio editorial para nuestro continente}

En julio de 2013 se realizó en Buenos Aires el XVIII Congreso Internacional de Hispanistas. En esa oportunidad, invitado a pronunciar la conferencia de apertura, procuré trazar un panorama sobre los principales proyectos editoriales en América Latina, a partir de un doble recorte: me referí solo al siglo XX, y al libro de literatura. Aquella conferencia se publicó con el título "Editores y políticas editoriales en América latina” (2015: 19-47). El objetivo que allí perseguía era bien evidente: postular la necesidad de superar las barreras nacionales en nuestros estudios sobre historia de la edición. Esa necesidad partía de mi propia experiencia: de 2006 es la primera edición de nuestro libro Editores y políticas editoriales en Argentina, publicado por el Fondo de Cultura Económica. Una y otra vez, durante la escritura de aquel libro, me enfrenté con un clásico problema metodológico: ¿cómo aislar a ese objeto, el libro y la edición en Argentina, cada vez más integrado a un mercado mundial? Hablar de ese objeto implicaba una suerte de recorte artificial, ya que, podríamos decir, nuestro libro se detenía allí donde el mercado no se detenía. Me convencí, entonces, de que era menester ampliar nuestro enfoque y, por ende, complejizarlo, y eso intenté en aquella conferencia. En esta, mi propósito, por un lado, se diversifica; por otro, se profundiza. Se diversifica porque esta vez incluyo el concepto de redes intelectuales; esto es, conjugo la historia de la edición con la historia de las ideas, lo cual, como sabemos, no tiene nada de original. Y se profundiza porque trataré de evitar el esfuerzo panorámico para focalizar, con más detalle, en un par de casos significativos ${ }^{1}$.

\section{Americanismo / latinoamericanismo}

En primer lugar, procuraré deslindar dos ideologías de un modo elemental, sintético: por un lado, lo que solemos llamar americanismo, a menudo simplificado

1 Una versión previa de este artículo fue publicada en mi libro Los autores no escriben libros. Nuevos aportes a la historia de la edición (de Diego 2019).

José Luis de Diego, Universidad Nacional de La Plata, Argentina

Ә Open Access. (c) 2021 José Luis de Diego, published by De Gruyter. (c) BY-NC-ND This work is licensed under a Creative Commons Attribution-NonCommercial-NoDerivatives 4.0 International License.

https://doi.org/10.1515/9783110713015-003 
como un humanismo de perfil continental, o de un vago utopismo progresista, que se consolida a partir de la revolución mexicana de 1910 y el movimiento reformista argentino, y se institucionaliza en partidos como el PRI (Partido Revolucionario Institucional) mexicano y el APRA (Alianza Popular Revolucionaria Americana) del Perú; por otro, el latinoamericanismo, sustentado por las llamadas teorías de la dependencia y del subdesarrollo, propiciador del concepto integrador de "Tercer Mundo", potenciado por la revolución cubana de 1959 y diseminado en numerosas organizaciones a lo largo de nuestro continente: las más emblemáticas, Casa de las Américas, de La Habana, y la Fundación Centro de Estudios Latinoamericanos "Rómulo Gallegos”, de Caracas. Por supuesto, se pueden rastrear los fundamentos políticos de tales ideologías y advertir cómo se va pasando de un socialismo reformista, con componentes más o menos marcados - según los países y regiones- de indigenismo y de nacionalismo; a un socialismo revolucionario que convocaba a la lucha por el poder por la vía armada en un proceso vertiginoso de radicalización política que ocupa las décadas de los sesenta y setenta. Sin embargo, cuando el objetivo que perseguimos es poner en relación redes intelectuales con proyectos editoriales, resultan más pertinentes conceptos amplios y abarcativos, como americanismo, y no específicos y más restringidos, como socialismo reformista; aunque existen, claro está, sólidos proyectos editoriales ligados a partidos políticos de nítido encuadre ideológico. La amplitud de los conceptos, no obstante, no atenúa su operatividad ni su vigencia.

Solo a manera de ejemplo, una breve anécdota. Hacia mediados de los noventa estábamos discutiendo la reforma del plan de estudios de la carrera de Letras de la Universidad Nacional de La Plata. Susana Zanetti, una de las más brillantes americanistas que dio nuestro país, insistió en que las asignaturas que se llamaban Literatura Hispanoamericana debían llamarse Literatura Latinoamericana; esa actitud no tenía que ver con recortes de sentido -qué abarca lo "hispano", qué abarca lo "latino"-, sino que constituía una afirmación generacional e ideológica, diríamos latinoamericanista. Lo que me interesa analizar es, entonces, la centralidad de algunos emprendimientos editoriales en la difusión y consolidación de idearios específicos; no en el sentido de que tal o cual editorial fue el instrumento de esa doctrina, sino en el sentido inverso: la doctrina existió para la comunidad lectora gracias a la visibilidad que le otorgó tal o cual editorial, lo que equivale a decir más o menos lo mismo, pero metodológicamente hay que recorrer otro itinerario. Por ejemplo, no limitarse al análisis del catálogo y estudiar también las políticas comerciales de expansión americanista de los sellos más influyentes; quiero decir: no solo considerar el americanismo como un conjunto de ideas, sino también como una operación que incluye el impacto cultural y la proyección comercial de determinados catálogos 
en nuestro continente. Quizás una aproximación a la historia y al catálogo del Fondo de Cultura Económica de México (FCE) permita ver más de cerca el deslinde que procuro trazar.

No voy a reseñar los orígenes y desarrollo del Fondo porque son harto conocidos (Díaz Arciniega 1996; Sorá 2017: 53-99), sino focalizar en el ideario que diseña y construye. En la "Nota preliminar” del Catálogo general de 1964 se exhiben con orgullo las cuatro líneas directrices que guiaron la trayectoria del Fondo: 1) se trata de una institución de bien público, de servicio cultural (es decir, sin fines de lucro); 2) conserva una ética editorial (no atada a las modas comerciales, ni a las demandas primarias del mercado); 3) "aspiración humanista"; 4) vocación americanista ("fidelidad a la significación, perdurable y potencial, de Iberoamérica”). Toda vez que se ha hecho referencia al americanismo del Fondo se ha señalado, y con muy buenos argumentos, la importancia y trascendencia de su catálogo. Analizados los dos catálogoslibro que el Fondo publicó en 1955 y en 1964 (en las respectivas celebraciones de sus veinte y treinta años de vida), se advierte un itinerario que podría sintetizarse en tres etapas o momentos (Sorá 2017: 59-70):

- la primera, ligada al proyecto original de Cosío Villegas desde la Escuela de Economía, privilegia las colecciones de economía y sociología, con una vocación de modernización del pensamiento y de introducción, para América latina, de las novedades intelectuales del mundo;

- la segunda responde acabadamente al proyecto americanista, representado por el lanzamiento de la colección Tierra Firme en 1944 ("una hora de la conciencia hispanoamericana”; en el catálogo de 1955 se registran 57 títulos y 5 volúmenes especiales), de la Biblioteca Americana en 1947 (36 títulos para 1955; luego el ritmo de la colección se desacelera) y Letras Mexicanas en 1952 (que se inicia con el lanzamiento de la Obra poética, de Alfonso Reyes);

- la tercera, a la que podríamos llamar de popularización, corresponde a la centralidad de colecciones de bolsillo y más accesibles al gran público, como Breviarios (se inicia en 1948; para 1964 se habían publicado 175 títulos) y la Colección Popular (se lanza en 1959; en el catálogo del 64 ya registra 50 títulos).

Como se ve, es durante la segunda y tercera etapas, desde mediados de los cuarenta, cuando el americanismo se acentúa. Sin embargo, es posible brindar otra mirada sobre el americanismo del proyecto editorial, focalizando en las políticas de expansión e intercambio comercial, en el marco de las migraciones políticas e intelectuales de Nuestra América y de los vaivenes económicos que fueron modificando su fisonomía. Según lo ha sugerido Gustavo Sorá (2017: 73ss.), fue con la 
colección Tierra Firme que el Fondo encontró el vehículo de difusión y unificación simbólica del ideario americanista. Mediante la colección, Cosío fue afianzando un género a medio camino entre la historia, el ensayo y la literatura que será, con el tiempo, fácilmente identificable como una marca distintiva del sello. Acaso Muerte y transfiguración de Martín Fierro, el clásico ensayo de Ezequiel Martínez Estrada de 1948, represente uno de los mejores ejemplos de ese género y de esa marca. En una carta de diciembre de 1941, Cosío sostiene "que los libros deben ser escritos en un lenguaje llano, y en un estilo literario tan atractivo como sea posible, sin aparato documental o erudito alguno y el autor debe ponerse en el lugar de reconocer que sus lectores ignoran antecedentes o consecuentes de lo que él habla"; y agrega más adelante: "Ya sabe usted que la empresa, más que de una importancia comercial, lo es moral” (citado por Sorá 2017: 88). Sin embargo, los textos de Cosío de fines de los cuarenta demuestran que también había que dar una batalla comercial para desarrollar un espacio americano. En una conferencia pronunciada en la UNAM en 1947, minimiza el impacto de la Guerra Civil española en el despertar editorial de los principales centros americanos: "Mucho más importante fue que para esas fechas principiaban a recogerse los frutos de la acción educativa más vieja y pausada en Chile y Argentina, o la más reciente pero vigorosa de México . . .” (Cosío [1947] 2005: 9). Y dos años después, en 1949, da a conocer un artículo que desde su título, provocativo y ambicioso, discute centralmente cuál era, en aquella coyuntura, el meridiano editorial en lengua española: "España contra América en la industria editorial”. Allí afirma:

La guerra civil hizo emigrar a América a algunos intelectuales españoles que encontraron pronto acomodo como valiosos colaboradores de las nuevas editoriales hispanoamericanas; emigraron a América, asimismo, algunos trabajadores gráficos pero, sobre todo, elementos directivos de la industria editorial española que se pusieron al frente de editoriales americanas. Contra estos hechos, de cuya gran significación no es posible dudar, están otros en los que poca o ninguna influencia pudo haber tenido la guerra civil española. $\mathrm{Ni}$ en la Argentina misma, en donde las empresas editoriales proliferaron de modo desconcertante, se dio el caso de un solo taller de imprenta fundado por los exiliados políticos españoles; lo mismo, exactamente, ocurrió en Chile y en México. Esto quiere decir que toda la industria de artes gráficas en que se apoyó la nueva industria editorial latinoamericana existía íntegra antes y que los nuevos talleres que se fundaron (varios en la Argentina, y no más de tres en México) son de nacionales latinoamericanos (1949: 61).

No resulta demasiado difícil refutar la enfática afirmación de Cosío; por lo visto, sus desmesurados argumentos solo buscaban discutir la hegemonía de España; claro está, en 1949, en el período más bajo de producción de libros en la península. Lo que quiero decir es que el americanismo ya se puede encontrar en el catálogo, pero también en las batallas ideológicas y en la lucha por la hegemonía 
en un mercado específico. En este sentido, la posición de Cosío tuvo su equivalencia en las decisiones políticas y comerciales que se fueron tomando desde el Fondo. Se abrió una sede en Buenos Aires en 1945 (y se encargó su dirección, como es sabido, a Arnaldo Orfila Reynal); y siguieron: en Santiago de Chile en 1954, en Lima en 1961, en Madrid en 1963 (con la lúcida dirección de Javier Pradera), en Caracas en 1974, en Bogotá en 1975. Los catálogos antes mencionados marcan una diferencia entre "sucursales" y "representaciones", pero es posible advertir que en algunos casos lo que era una mera "representación” con los años se transformó en "sucursal”; así, el catálogo de 1955 menciona las de Argentina, Brasil, Colombia, Chile, España, Perú y Uruguay; el del 1964 añade la de Venezuela. Cuando en 1948 se hace cargo de la dirección del Fondo, Orfila Reynal reforzará el proyecto de Cosío acentuando, como ya hemos dicho, el carácter más masivo de las colecciones que lanza, como Breviarios y la Colección Popular.

\section{Sobre la Editorial Ercilla}

La evolución de la editorial Ercilla es menos conocida. Bernardo Subercaseaux le dedicó unos párrafos en su historia del libro en Chile (2000: 112-116) y los estudiosos del APRA peruano, como Ricardo Melgar Bao (2010) y Martín Bergel (2013), se han detenido en el proyecto editorial en tanto formación ideológica que proyecta y materializa el pensamiento de los principales referentes del movimiento. Pero el documento de mayor interés lo constituyen las memorias de Luis Alberto Sánchez, quien fuera director de Ercilla durante parte de su exilio chileno; Visto y vivido en Chile se publicó en 1976, y se abre con una dedicatoria a su amigo Pablo Neruda, ya fallecido ${ }^{2}$. El Chile de los años treinta hasta mediados de los cuarenta albergó una intensa vida política, intelectual y artística; en un par de ocasiones, Sánchez utiliza la metáfora del “oasis” para los exiliados de países hermanos que encontraron allí su lugar de refugio. La nómina de los intelectuales que temporariamente recalaron en Santiago por aquellos años llama la atención si tenemos en cuenta su proyección futura:

De ese Santiago agitado y cosmopolita salieron varios presidentes de la República de diversos países del mundo: [Rómulo] Betancourt, [Alfonso] López Michelsen, [Hernán] Siles Suazo, [José María] Velazco Ibarra, Bonilla, [Víctor] Paz Estenssoro y cuántos se me olvidan.

2 "Después de leer tu libro póstumo Confieso que he vivido, memorial fino, profundo, cosmopolita, provinciano e incompleto, sentí más la urgencia de escribir y publicar el libro que tú quisiste de mí. Helo aquí, Pablo, desprovisto de retórica y de hipocresía” (1976: 12). 
Y Rectores, legisladores y hasta Dictadores. Chile era una caldera hirviente. Y al mismo tiempo -oh, paradoja- un oasis sombreado y fresco (Sánchez 1976: 87).

La editorial Zig-Zag se fundó en 1905 y su principal referente fue Guillermo Helfmann, un inmigrante alemán que había sido administrador de El Mercurio; y Ercilla se fundó en 1928: ambas son los vértices más visibles de aquel período floreciente. Algunas peculiaridades caracterizaron la labor editorial en Ercilla. Si bien el principal socio capitalista y presidente del directorio era un chileno de alcurnia, don Ismael Edwards Matte, y el "factótum" de la editorial era un argentino, Laureano Rodrigo; desde fines de 1934 (Sánchez ingresó a Ercilla el 17 de diciembre) los exiliados peruanos del APRA fueron ocupando lugares importantes y estratégicos en la conducción de la empresa. La lectura que el propio Sánchez hace de esa presencia resulta verosímil: ni la dirección de Ercilla tenía una especial simpatía ideológica por el APRA, ni los peruanos se propusieron hacerse progresivamente del control del sello; ocurrió que los intelectuales peruanos resultaban eficientes en el trabajo y se les podía pagar menos, porque, en situación de exilio, necesitaban imperiosamente conseguir un sustento de vida. De manera que por allí pasaron, además de Sánchez, Manuel Seoane -quien fuera director de la popular revista Ercilla-, Ciro Alegría -allí se publicó, en 1941, la primera edición de El mundo es ancho y ajeno-, Juan José Lora, Luis López Aliaga, Bernardo García Oquendo y Pedro Muñiz, todos ellos vinculados al APRA. Una vez que se asentaron en la editorial, debieron soportar los embates de sectores nacionalistas que se referían al sello despectivamente como "una editorial peruana". En una conocida síntesis, Sánchez afirma que "Chile empezaba a ser un centro editorial. Publicaba mucho, aunque mal” (1976: 33). Lo curioso es que ese diagnóstico, según la mirada del memorialista, tenía un alcance autocrítico: también incluía a Ercilla. La conducción editorial imprimió un ritmo vertiginoso; el objetivo de editar un título por día los llevó a contar, hacia fines de 1936, con 800 títulos en el catálogo. Era, además, y diríamos que principalmente, una editora de revistas, entre las que sobresalían Hoy, a cargo de Edwards Matte, y Ercilla, dirigida por Seoane; así, podemos conjeturar que la edición de libros estuvo contagiada por el ritmo de las revistas. En ese vértigo había que hacer de todo, y es frecuente en los testimonios el recuerdo de Ercilla como un lugar de intenso aprendizaje. "Mucho, aunque mal", dice Sánchez, y alude a que la cantidad conspiraba contra la calidad: Ercilla parece reproducir los males de las editoriales americanas de gran alcance popular que, en la voluntad de lograr una llegada mayor, descuidan la calidad de los productos. Traduciendo contra reloj sin los controles necesarios, editando autores extranjeros sin pagar derechos (se la acusaba de tener numerosas ediciones piratas), retribuyendo a sus trabajadores con salarios magros, Ercilla tuvo su momento de 
auge entre 1935 y 1937; en 1938, con el alejamiento de Rodrigo y la llegada de un gerente belga, comenzó, según Sánchez, la decadencia del sello: "El ritmo de ediciones se hizo más lento: dos libros por semana. Se aumentaron los precios, se mejoró la presentación. Se melló el vínculo fraternal que nos reunía a chilenos, peruanos, españoles y otras nacionalidades en las tareas y esparcimientos ercillescos” (1976: 47). Resulta evidente que para Sánchez, conspicuo dirigente del APRA, sus intereses empezaban a ser diferentes a los de la empresa, y el precario equilibrio entre proyecto intelectual y objetivos comerciales comenzó a agrietarse.

El catálogo de Ercilla revela, como muchas empresas editoriales de los treinta, un carácter ecléctico: existen unos pocos títulos que suelen citarse como representativos y cientos de otros que completan un listado misceláneo y de perfil comercial. El sector del catálogo más reseñado corresponde precisamente a los libros apristas: El antimperialismo y el APRA y Excombatienetes y desocupados de Víctor Raúl Haya de la Torre, Nuestra América y la guerra de Manuel Seoane, Pueblo continente de Antenor Orrego, Penetración imperialista de Pedro Muñiz y Carlos Manuel Cox, entre otros. A los que deben añadirse los numerosos títulos de Sánchez, como Panorama de la literatura actual, Haya de la Torre o el político, Vida y pasión de la cultura en América. En muchos casos, se trata de textos militantes, de divulgación y debate, que buscaban cauce en Ercilla, pero también lo hacían en Buenos Aires, a través de Claridad o Gleizer, y en otras capitales americanas. Respecto de títulos específicamente literarios de autores locales, el análisis del catálogo, y de las trayectorias editoriales de los escritores, confirma el panorama trazado por Sánchez. Muchos de los autores iniciaron su carrera a través de Nascimento, la editorial identificada con la vanguardia literaria chilena ${ }^{3}$; aparecieron, en los años de auge, algunos títulos en Ercilla, y después de 1938 ya buscaron otros rumbos. El caso más conocido es el de Neruda, que después de pasar por Nascimento con títulos como Veinte poemas de amor ... y Tentativa del hombre infinito, cedió ante la insistencia de Sánchez y publicó en Ercilla España en el corazón en 1937, y poco después comenzó a publicar regularmente en Losada. Algo parecido ocurrió con la obra del novelista y cronista Joaquín Edwards Bello: desde los años veinte y en adelante dio a conocer numerosos títulos en Nascimento y su obra de madurez se publicó en Zig-Zag; sin embargo, entre 1934 y 1935 tres de sus títulos fueron editados por Ercilla. Similar itinerario se advierte en la obra de Benjamín Subercaseaux, de José Diez Canseco -Ercilla logra editar Duque, su novela más conocida, en 1934-, e incluso del notable poeta Vicente Huidobro. En este sentido, las memorias de Sánchez, que nunca caen en la seducción de la egolatría, nos dicen la

3 Según Subercaseaux, Nascimento llegó a publicar 70 títulos de autores nacionales por año (2000: 112). 
verdad: los años de auge del sello coinciden con su labor como vicedirector y luego como director: la mayor inserción de Ercilla en las redes artísticas e intelectuales chilenas y latinoamericanas tuvo que ver con las relaciones personales que Sánchez fue armando trabajosamente con escritores, ensayistas y poetas. Por otro lado, buena parte del catálogo incluye literatura traducida en la que conviven algunos clásicos modernos, como Thomas Mann, Virginia Woolf y André Malraux con best sellers de aquellos años como Margaret Mitchell y Pearl S. Buck.

El argumento de Cosío Villegas que hemos comentado parece adecuarse mejor a la evolución editorial chilena que a la argentina y mexicana; en Chile, la consolidación de las empresas más importantes es anterior a la Guerra Civil de España y la llegada de exiliados tiene un impacto menor en el mundo del libro. Por esta razón, Castillo García ha afirmado que "Chile no supo o no pudo aprovechar la llegada de los españoles al país” (2000: 197). En este sentido, suelen mencionarse a Joaquín Almendros -quien llegó a Valparaíso en el legendario buque Winnipeg en 1939, y fue el creador de la librería y editorial Orbe- y a Arturo Soria, fundador de la editorial Cruz del Sur, un sello en origen pequeño que dio a conocer la primera edición chilena de Altazor. No obstante, si tomamos en cuenta su proyección continental, Ercilla -aunque de catálogo más ecléctico y menos programático - tuvo idéntica vocación que el Fondo: a partir de 1936 comenzó a abrir sucursales en Caracas, Buenos Aires, México, San José, Montevideo y tuvo agentes en las principales ciudades del continente (Sánchez 1976: 43) ${ }^{4}$. Ahora bien, esta notable coyuntura intelectual que se dio en Santiago de Chile entre los treinta y los cuarenta, como otras que se pueden detectar, según veremos, en Nuestra América, parecen confirmar supuestos metodológicos largamente reseñados (de Diego 2019: 13-32): más allá de las variables cuantitativas que tienen que ver con una coyuntura económica favorable, es necesario detenerse en variables cualitativas que resultan decisivas al momento de evaluar el período: la situación de Santiago como refugio de exiliados, el florecimiento de círculos intelectuales y artísticos, la vigorosa vida cultural, la gran capacidad de circulación de ideas y libros en otros centros intelectuales del continente, la iniciativa de notables editores como Luis Alberto Sánchez, hicieron de ese lugar y de aquellos años un foco de interés muy significativo para la historia de la edición.

4 Al listado de sucursales que enuncia Sánchez, Subercaseaux añade Cuba y Colombia (2000: 113). 


\section{Algunas hipótesis sobre Sudamericana}

A diferencia del Fondo y de Ercilla, Sudamericana de Buenos Aires no fue una editorial a la que podamos atribuir el mote de americanista. A poco de ser fundada, y luego de una serie de traspiés económicos, se hicieron cargo de la empresa Antonio López Llausás y Julián Urgoiti, dos españoles que contaban ya con experiencia en el mercado del libro. Consultado un catálogo de 1945, se contabiliza un número llamativo de títulos traducidos -en especial, en la conocida colección Horizonte- y se observa una voluntad de combinar nombres consagrados de la literatura con episódicos éxitos de venta. En contraste con Losada y Espasa-Calpe Argentina, no hay, en el catálogo de Sudamericana, una llamativa presencia de autores españoles. En los años cuarenta, lo moderno en cultura se identificaba con lo anglosajón y en Sudamericana se nota esa voluntad de modernidad; un sello actual, ecléctico y comercialmente sólido; en el país, se relacionó desde sus inicios con la vanguardia del grupo Sur, una elite muy atenta a lo producido en el exterior y cuyo americanismo tuvo características diferentes al que por los mismos años se difundía desde el Fondo y Ercilla (Sarlo 1983; Gramuglio 1985). Por su parte, Gloria López Llovet (2004: 43) comenta que su abuelo, López Llausás, acaso temeroso por "el advenimiento del peronismo" decidió abrir dos sedes en el extranjero; así nacieron, a fines de los cuarenta, una filial en México a la que llamó Hermes y otra en Barcelona: Edhasa. En rigor, se trataba de casas distribuidoras de Sudamericana, aunque en el caso de Hermes ya había publicado libros con ese sello.

Pero, además, y confluyente que lo que venimos diciendo, hay otro hecho relevante en el diseño del catálogo de Sudamericana. En esos mismos años, fines de los cuarenta, la editorial publicó El túnel de Ernesto Sabato y Adán Buenosayres de Leopoldo Marechal; y solo tres años después, Bestiario de Julio Cortázar y Misteriosa Buenos Aires de Manuel Mujica Láinez. No sabemos por qué la editorial comenzó a apostar más fuerte por la literatura nacional, prácticamente ausente en el catálogo de 1945; pero podemos conjeturar una hipótesis: a medida que se iban perdiendo mercados externos por la creciente recuperación de la industria española, algunos sellos, y en especial Sudamericana, empezaron a apuntar al creciente mercado interno como estrategia de supervivencia; sobre todo cuando España deja de importar masivamente libros desde Argentina. De manera que si el americanismo fue, para los años treinta, una opción ideológica, este nuevo americanismo de los cincuenta es más bien una alternativa comercial; y, en esta precisa coyuntura, Sudamericana hizo, como suele decirse, de la necesidad una virtud. Podemos señalar, entonces, una suerte de paradoja: que la editorial que protagoniza la recuperación del mercado interno y da visibilidad al inicio del llamado boom de la narrativa latinoamericana no se 
identificaba con otros sellos, como Losada y Claridad - concebidos sobre todo como proyectos culturales-, sino más bien que descubre ese camino como parte de un oportuno golpe de timón comercial. Pero es una paradoja aparente, porque el americanismo tradicional podía representar, en un mercado como el porteño, algo residual; en tanto el nuevo latinoamericanismo irrumpía con la fuerza del juvenilismo, lo transgresor y lo genuinamente actual, como si se tratara, en verdad, de una nueva vanguardia. En otro lugar he procurado demostrar cuáles fueron las razones de la pérdida de la centralidad de Losada en el mercado argentino (de Diego 2015: 141-164): acaso una concepción estética demasiado estrecha o conservadora por parte de quienes tomaban las decisiones fueron dejando a la editorial al margen de los procesos de renovación literaria. Sudamericana, en este sentido, representa la contracara: la participación directa de Francisco Porrúa - uno de los más notables editores de nuestro país- en la elaboración del catálogo fue confirmando el aserto de la mirada hacia lo nuevo, y lo nuevo tuvo, por aquellos años, el sello de lo latinoamericano; se iniciaba, de este modo, un proceso de captación de autores y obras que le permitirá colocarse en el centro de la escena ya entrados los años sesenta, como lo confirman los llamativos índices de venta de novelas emblemáticas del período: Sobre héroes y tumbas (Ernesto Sabato, 1961), Rayuela (Julio Cortázar, 1963), Cien años de soledad (Gabriel García Márquez, 1967), Boquitas pintadas (Manuel Puig, 1969), entre otras.

Hemos hablado de la expansión del Fondo de Cultura Económica, a partir de 1945, hacia el sur y hacia España; también de las sucursales y representaciones que fue abriendo Ercilla desde fines de los treinta, y de Hermes y Edhasa, las subsidiarias de Sudamericana fundadas a fines de los cuarenta. Expansión e intercambio que tienen una doble faz: por un lado, la labor fundamental de editoriales latinoamericanas en la superación de las fronteras nacionales de nuestras literaturas -conexiones rizomáticas que desmienten la insistencia de buena parte de la bibliografia peninsular en privilegiar la centralidad catalana en el descubrimiento de la literatura latinoamericana para los latinoamericanos-; por otro, la conformación de sólidas redes intelectuales: a medida que uno va rastreando las historias nacionales del libro y la edición, resulta evidente que todas se encuentran atravesadas por una realidad continental de editores migrantes, intelectuales y escritores nómades, dictaduras que expulsan a sus mejores hombres quienes, a su vez, contaminan los países hermanos.

\section{Sobre Monte Ávila y la Biblioteca Ayacucho}

Hace casi veinte años, Susana Zanetti (1998) advertía sobre las dificultades que deben sortearse para constituir un canon latinoamericano; y en esa labor, para 
fijar y estabilizar un canon para el continente, nada más necesario que una biblioteca. Zanetti destaca dos célebres y necesarios antecedentes en esta tarea: La Biblioteca Americana del Fondo de Cultura Económica, que proyectó, aunque no alcanzó a dirigir, Pedro Henríquez Ureña; y la Biblioteca Ayacucho, que diseñó y dirigió hasta su muerte Ángel Rama. Y esta mención de la notable colección de Rama nos transporta a otro núcleo de interés y condensación de significaciones en la historia de la edición: me refiero a la Venezuela de fines de los sesenta y los setenta. Venezuela sufrió dictaduras que llevaron al exilio a intelectuales y escritores; de hecho, en el Chile de los treinta que reseñamos más arriba recalaron Rómulo Betancourt, Juan Oropeza, Mariano Picón Salas ${ }^{5}$, entre otros que huían de la dictadura de Juan Vicente Gómez. Pero aquella Venezuela de la diáspora se transformó, ya en los sesenta, en tierra de acogida. Si fijamos nuestra atención, una vez más, en las redes intelectuales que superaron las barreras nacionales y encarnaron en proyectos editoriales, así como nos detuvimos en el exilio peruano en el Santiago de Ercilla y Nascimento, es menester detenernos ahora en el exilio uruguayo en Caracas.

En su conocido “Diario de Caracas”, de 1967, el crítico uruguayo Emir Rodríguez Monegal anota en el 13 de agosto, su último día:

Me acompañan al aeropuerto Simón Alberto y Guillermo Sucre. Allí terminamos de hablar de un gran proyecto en que está comprometido ahora el INCIBA: una editorial venezolana modelada sobre el Fondo de Cultura Económica de México y la Editorial Universitaria de Buenos Aires. Se llamará Monte Ávila y tendrá a Benito Milla, de la editorial uruguaya Alfa, como gerente; el asesor literario será Sucre. Se proyectan varias colecciones venezolanas, latinoamericanas e internacionales; se piensa publicar una cantidad no inferior a cincuenta títulos, con un total de 200.000 ejemplares por año. Creo que Venezuela es uno de los lugares más estratégicos para una empresa de esta índole. A mitad de camino entre las grandes industrias editoriales del Norte (Estados Unidos y México) y las del Sur (Río de la Plata y Chile), Venezuela tiene un papel muy importante que cumplir en la zona grancolombiana, y la gente del INCIBA parece dispuesta a cumplirlo. Ya sabía por Milla del proyecto pero me alegra mucho enterarme ahora que empieza a funcionar en octubre (2002: 634).

Expliquemos el alcance del testimonio: el gobierno de la Acción Democrática tomó la iniciativa de crear un sello editorial del Estado y encomendó la tarea a Simón Alberto Consalvi, quien estaba al frente del Instituto Nacional de Cultura y Bellas Artes (INCIBA); en esa dirección, las dos decisiones del INCIBA son particularmente significativas: por un lado, tomar como modelos a dos destacados emprendimientos (el FCE y Eudeba) que tienen participación estatal pero

5 En el capítulo "En la "fértil provincia señalada” de su Viejos y nuevos mundos, Picón Salas rememora sus años de exilio en Chile (1983: 571-579). 
un alto grado de autonomía; por otro, involucrar en el proyecto a dos figuras del mundo editorial y académico de Uruguay, como Milla y Rodríguez Monegal. De manera que en la génesis de Monte Ávila se observa una saludable actitud de apertura: en inspirarse en modelos externos reconocidos y exitosos, y en convocar a hombres de experiencia editora, aunque fuesen extranjeros. La iniciativa junto a la que algunos años después dio origen a la Biblioteca Ayacucho- configura lo que Arráiz Lucca llamó el "Estado editor” (2000: 256), un modelo muy propio de Venezuela que se diferencia ostensiblemente de tradiciones más identificadas con las empresas privadas, como en Colombia y en Chile.

Por su parte, la diáspora uruguaya comenzó durante la corta presidencia de Óscar Gestido y se acentuó a partir de 1967, durante la gestión de Jorge Pacheco Areco; ante el crecimiento de la resistencia social y de la acción de las organizaciones guerrilleras, Juan María Bordaberry ejecutó un autogolpe de Estado cívico-militar en 1973 y se erigió en presidente de facto; a lo largo de ese convulsionado período, numerosos intelectuales y escritores debieron abandonar el país. Alejandra Torres (2012) ha reconstruido el itinerario editorial de Benito Milla, un inmigrante alicantino que recaló primero en Buenos Aires, pero debido a su actividad libertaria y antiperonista debió radicarse en Montevideo; allí, en 1958, editó el primer libro con el sello Alfa. A través de sus nueve colecciones, en especial en Carabela, Alfa dio a conocer lo mejor y más novedoso de la literatura oriental. Durante los primeros años, Ángel Rama acompañó a Milla en su "aventura” editorial; en 1960, dirigía la colección Letras de Hoy y allí trabajó dos años: en esa colección se publicaron en total diez libros de autores nacionales; dos de ellos, Juan Carlos Onetti y Felisberto Hernández, clásicos contemporáneos de Uruguay, fueron relanzados en ediciones de mayor llegada al público. A partir de esta experiencia del mundo editorial, y de su continua tarea como prologuista, Rama sentará las bases de la Editorial Arca, la otra editorial montevideana emblemática de aquella época, que surge poco tiempo después, a comienzos de 1962. Alfa y Arca, entonces, marcaron el ritmo del mercado del libro literario en Uruguay, dieron respuesta a la avidez de una clase media en ascenso, actualizaron sus catálogos con las nuevas tendencias en literatura y crearon las condiciones de posibilidad para el surgimiento y afirmación de una generación de jóvenes como Eduardo Galeano, Juan Carlos Legido, Mario César Fernández y Cristina Peri Rossi. En 1966, y como consecuencia de las turbulencias políticas que sacudian a Uruguay, Milla fundó, con Héctor A. Murena, la Editorial Alfa Argentina, y ese mismo año emigró a Venezuela; su hijo Leonardo quedó a cargo de Alfa uruguaya y argentina. Por entonces, Emir Rodríguez Monegal se había embarcado en el proyecto de la revista Mundo Nuevo; como director de la publicación entre 1966 y 1968, estuvo en el centro de un conflicto ideológico que suele sintetizarse como "guerra fría 
cultural"6; según ha demostrado María Eugenia Mudrovcic (1997), el conflicto tuvo uno de sus momentos críticos en la entrega del premio Rómulo Gallegos a La casa verde de Mario Vargas Llosa en 1967, precisamente el episodio que reseña Rodríguez Monegal en su ya citado "Diario de Caracas”.

Ahora volvamos a Monte Ávila, fundada en Caracas en 1968. En su estupendo catálogo se advierte una tensión que puede haber derivado en los disensos internos que llevaron a la renuncia de Milla en 1970. Por un lado, si se trataba de una editorial venezolana, financiada con fondos públicos, debía otorgar un lugar visible a la literatura del país. Por esa razón, allí conviven clásicos del siglo XIX (Eduardo Blanco, Manuel V. Romero García), autores del pasado reciente más o menos consagrados (Rómulo Gallegos, José Rafael Pocaterra, Arturo Uslar Pietri, Antonia Palacios, Salvador Garmendia, Vicente Gerbassi, Alfredo Armas Alfonzo); escritores emergentes (Eduardo Sifontes, Laura Antillano, Rafael Zárraga, Oswaldo Trejo), poetas (Hesnor Rivera, Francisco Pérez Perdomo) y dramaturgos (Rafael Santana). Por otro, se pone en marcha un notable proyecto de modernización teórica y cultural, con un conjunto de títulos que abarcan los temas de la agenda de fines de los sesenta (polémicas en el seno del marxismo, industrias culturales, drogas, sexualidad, arte y sociedad) mediante firmas que irán ocupando un lugar central en los debates ideológicos y estéticos. A manera de ejemplo, mencionaré algunos títulos: La Ilustración y la sociedad actual de Lucien Goldmann (1968), El libro que vendrá de Maurice Blanchot (1969), Intervenciones. Nueve modelos de crítica de Theodor Adorno (1969), Orden y caos de Urs Jaeggi (1969), Una vida violenta de Pier Paolo Pasolini (1969), Sobre el programa de la filosofía futura y otros ensayos de Walter Benjamin (1970), La muerte de la tragedia de George Steiner (1970), Ya no es posible callar de Roger Garaudy (1970), y más adelante, Harold Bloom, Jean Baudrillard, Leszek Kolakowski, Bernard Henri-Lévy, Gaston Bachelard ${ }^{7}$. . . Una mención especial merece el interés que prestó la editorial en propiciar la crítica literaria latinoamericana: tempranamente editó dos trabajos ya canónicos, Borges el poeta de Guillermo Sucre (1968) y El otro Andrés Bello (1969), el elaborado estudio de Rodríguez Monegal; años después, Rufino Blanco Fombona íntimo de Ángel Rama (1975) y El espejo hablado, el pionero análisis de Cien años de soledad de Suzanne Jill Levine (1975).

\footnotetext{
6 Sobre la "guerra fría cultural" en América latina, pueden consultarse, además de Mudrovcic, a Claudia Gilman (2003) y Gustavo Sorá (2008).

7 Gustavo Valle (2012), a partir del testimonio de Juan Liscano (presidente del sello entre 1979 y 1984), destaca el papel relevante que jugaron los traductores argentinos en Monte Ávila: Héctor Murena, Roberto J. Vernengo, Norberto Silvetti Paz, Alberto Girri, Hugo Gola, Attilio Dabini, Enrique Revol, Héctor Libertella, Enrique Pezzoni, entre otros.
} 
Según lo adelantamos, en 1970 Milla dejó Monte Ávila tras una fuerte polémica por discrepancias con la política editorial marcada por el nuevo gobierno, que consideraba inadecuado su programa de publicación de autores extranjeros. Además, como también ocurrió en el FCE respecto de Orfila, con el tiempo cierto provincianismo caraqueño (del que solía renegar Ángel Rama en su Diario) comenzó a cuestionar las figuras extranjeras al frente de un sello del Estado. Fundó entonces en 1971, con Miguel Otero Silva y también en Caracas, la editorial Tiempo Nuevo. En 1974, con la gestión presidencial de Carlos Andrés Pérez, regresó a Monte Ávila como director general, pero, ante los cambios políticos tras la muerte de Franco, unos años después decidió regresar a España para fundar y dirigir, a partir de 1980, la Editorial Laia de Barcelona.

Sabemos que en los días de julio-agosto de 1972 que Rodríguez Monegal refiere en su "Nuevo diario de Caracas" Ángel Rama estaba en Venezuela; de hecho, sus intervenciones en el Coloquio del Libro organizado por el INCIBA motivaron largos comentarios críticos de Monegal, con duras referencias a su para entonces ya irreconciliable compatriota: incoherencias, agresividad, vedetismo ... (Gilman 2009). Y fue entonces en Venezuela donde sorprendió a Rama el golpe de Estado en su país de junio de 1973, de manera que lo que era una estadía de trabajo se convirtió en un exilio duradero. Según el propio Rama, el proyecto original de una biblioteca latinoamericana de grandes obras lo elaboró con el filósofo mexicano Leopoldo Zea y en su concreción tuvo participación directa el abogado venezolano José Ramón Medina, quien había estado ligado a Monte Ávila. En septiembre de 1974, el presidente Pérez firmó el decreto de creación de la Biblioteca Ayacucho; en ese año y en 1975 se realizaron reuniones preparatorias con intelectuales y especialistas de América latina, y el 8 de junio de 1976 salió de la imprenta el primer título, Doctrina del Libertador de Simón Bolívar. El ritmo de los primeros años - según queda registrado en el Diario de Rama- fue vertiginoso: en 1977, 1978 y 1979, se publicaron un promedio de 20 títulos por año; en años posteriores, que coinciden con estadías de Rama en Estados Unidos, ese ritmo fue decreciendo. Al momento de su muerte en 1983, la colección había superado los 100 títulos. Arráiz Lucca, en su panorama sobre la edición en Venezuela, no ahorra elogios al referirse a la Biblioteca: "es una joya, orgullo de la venezolanidad, [. . . E En pocas palabras, una colección de clásicos hispanoamericanos que no tiene parangón en toda América Latina” (2000: 257).

Ahora bien, tanto la génesis de la colección y su historia, como su envergadura y proyección han sido largamente estudiados (en especial, Pacheco y Guevara Sánchez 2003-2004) y no voy a repetir aquí lo ya sabido. Solo quiero agregar que, en la dirección de nuestras reflexiones, el americanismo heredado y el latinoamericanismo vigente encuentran en la Biblioteca su máximo momento 
de integración. Estamos en un nuevo ciclo de nomadismo político: una vez más, las égidas provocadas por las dictaduras generaron, como los españoles exiliados en México y Argentina, como los intelectuales peruanos en el Chile de los treinta, como los uruguayos en la Venezuela de los primeros setenta, que estamos reseñando, lugares de acogida en donde se rehabilitan los debates nacionales pero fuera de las fronteras. No obstante, fue la Biblioteca Ayacucho, sin duda, el proyecto menos nacional y más integrador de todos, el que logró un suficiente grado de autonomía y lucidez - no olvidemos que se trata de un programa financiado por el Estado venezolano- para dar a conocer autores relevantes y poco difundidos, para combinar los clásicos con lo más destacado del presente (Rulfo, Carpentier, Cortázar, Lezama Lima), para aunar tradiciones disímiles y aun enfrentadas - como las crónicas de conquistadores y las literaturas mayas o guaraníticas-, para sumar incluso a intelectuales de países como El Salvador y Panamá cuya literatura no tenía presencia continental, para convocar a brillantes intelectuales y académicos en la redacción de prólogos, estudios preliminares y cronologías.

\section{Coda}

No ignoro que los conceptos aquí reseñados de americanismo y latinoamericanismo han sido caracterizados de un modo precario y solo tentativo. Quizás su funcionalidad haya sido la de indicar transformaciones en el campo editorial que, como hemos dicho, alcanzan aspectos que exceden el señalamiento de mutaciones ideológicas. En la historia de la edición se suele partir del proyecto editorial y analizar en los logros, limitaciones y contrastes de un catálogo la encarnación de idearios teóricos, políticos y estéticos específicos. En esta oportunidad, intenté transitar el camino inverso y preguntarme de qué manera esas redes encontraron en la vía editorial el modo de afirmar, propiciar y difundir un conjunto de ideas. Dado que la historia de editoriales tan significativas como el FCE, Sudamericana o Eudeba ya está, en buena parte, escrita, creí que la focalización sobre Ercilla de Chile y Monte Ávila de Venezuela podía constituir un aporte original a nuestras investigaciones. No obstante, cuando de redes se trata, resulta indispensable pensar cada proyecto desde una perspectiva ampliada y comparativa que le otorgue, a cada uno de ellos, su justo alcance y significación: eso he procurado en estas notas. 


\section{Bibliografía}

Arráiz Lucca, Rafael (2000): “Imprentas y editoriales en Venezuela en el siglo xx: mínima crónica del furor por los libros”. En: Cobo Borda, Juan Gustavo (ed.): Historia de las empresas editoriales de América Latina. Siglo xx. Bogotá: Centro Regional para el Fomento del Libro en América Latina y el Caribe (CERLALC), pp. 253-270.

Bergel, Martín (2013): "Populismo y cultura impresa: La clandestinidad literaria en los años de formación del Partido Aprista Peruano”. En: Ipotesi. Revista de Estudos Literários 17/2, Universidade Federal de Juiz de Fora, julio-diciembre, pp. 135-146.

Castillo García, Eduardo (2000): “Reseña histórica de la industria editorial en Chile”. En: Cobo Borda, Juan Gustavo (ed.): Historia de las empresas editoriales de América Latina. Siglo XX. Bogotá: Centro Regional para el Fomento del Libro en América Latina y el Caribe (CERLALC), pp. 189-206.

Cosío Villegas, Daniel (1949): “España contra América en la industria editorial”. En: Cuadernos Americanos VIII/1, enero-febrero, pp. 59-71.

Cosío Villegas, Daniel (2005): “La industria editorial y la cultura”. En: Zaid, Gabriel (comp.): Daniel Cosío Villegas. Imprenta y vida pública. México: Fondo de Cultura Económica, pp. 1-26.

de Diego, José Luis (2019): Los autores no escriben libros. Nuevos aportes a la historia de la edición. Buenos Aires: Ampersand.

de Diego, José Luis (2015): La otra cara de Jano. Una mirada crítica sobre el libro y la edición. Buenos Aires: Ampersand.

de Diego, José Luis (ed.) (2014): Editores y políticas editoriales en Argentina (1880-2010). México/Buenos Aires: Fondo de Cultura Económica.

Díaz Arciniega, Víctor (1996): Historia de la casa. Fondo de Cultura Económica (1934-1996). México: Fondo de Cultura Económica.

Gilman, Claudia (2009): “El factor humano y una rivalidad histórica: Ángel Rama y Emir Rodríguez Monegal”. En: Maíz, Claudio/Fernández Bravo, Álvaro (eds.): Episodios en la formación de redes culturales. Buenos Aires: Prometeo, pp. 161-190.

Gilman, Claudia (2003): Entre la pluma y el fusil. Debates y dilemas del escritor revolucionario en América Latina. Buenos Aires: Siglo XXI.

Gramuglio, María Teresa (1985): "Sur en la década del treinta. Una revista política”. En: Punto de Vista IX/28, noviembre, pp. 32-39.

Guerrero, Gustavo (2018): Paisajes en movimiento. Literatura y cambio cultural entre dos siglos. Buenos Aires: Eterna Cadencia.

López Llovet, Gloria (2004): Sudamericana. Antonio López Llausás, un editor con los pies en la tierra. Buenos Aires: Dunken.

Melgar Bao, Ricardo (2010): “Huellas, redes y prácticas del exilio intelectual aprista en Chile”. En: Altamirano, Carlos (ed.): Historia de los intelectuales en América Latina, vol. 2. Buenos Aires: Katz Editores, pp. 146-166.

Mudrovcic, María Eugenia (1997): Mundo Nuevo. Cultura y Guerra Fría en la década del 60. Rosario: Beatriz Viterbo.

Pacheco, Carlos/Guevara Sánchez, Marisela (2003-2004): “Ángel Rama, la cultura venezolana y el epistolario de la Biblioteca Ayacucho". En: Estudios. Revista de Investigaciones Literarias y Culturales 22-23, Universidad Simón Bolívar, pp. 99-136. 
Picón Salas, Mariano (1983): Viejos y nuevos mundos. Selección, prólogo y cronología de Guillermo Sucre. Caracas: Biblioteca Ayacucho, 101.

Rama, Ángel (2001): Diario 1974-1983. Prólogo, edición y notas de Rosario Peyrou. Caracas: Trilce/La Nave Va.

Rodríguez Monegal, Emir (2002): “Diario de Caracas”. En: Revista Iberoamericana LXVIII/200, julio-septiembre, pp. 615-634.

Rodríguez Monegal, Emir (1973): “Nuevo diario de Caracas”. En: Revista Canadiense de Estudios Hispánicos (2ª época) 2/2-4, enero-diciembre, pp. 125-141.

Sánchez, Luis Alberto (1976): Visto y vivido en Chile. Bitácora chilena 1930-1970. Lima: Ediciones Unidas.

Sarlo, Beatriz (1983): “La perspectiva americana en los primeros años de Sur”. En: Punto de Vista VI/17, abril-julio, pp. 10-12.

Sorá, Gustavo (2017): Editar desde la izquierda en América Latina. La agitada historia del Fondo de Cultura Económica y de Siglo XXI. Buenos Aires: Siglo XXI.

Sorá, Gustavo (2008): “Edición y política. Guerra fría en la cultura latinoamericana de los años 60". En: Revista del Museo de Antropología 1, Facultad de Filosofía y Humanidades, Universidad Nacional de Córdoba, pp. 97-114.

Subercaseaux, Bernardo (2000): Historia del libro en Chile (Alma y cuerpo). Santiago de Chile: Lom Editores.

Torres, Alejandra (2012): Lectura y sociedad en los sesenta: a propósito de Alfa y Arca. Montevideo: Yaugurú.

Valle, Gustavo (2012): “Monte Ávila: el aporte argentino”. En: Clarín, 24/09/2012.

Zanetti, Susana (1998): “Apuntes acerca del canon latinoamericano”. En: Cella, Susana (ed.): Dominios de la literatura. Acerca del canon. Buenos Aires: Losada, pp. 87-105. 
